\title{
Comparison of the effect of different glide path Ni-Ti rotary systems on the formation of dentinal crack on curved root canals
}

\author{
Damla Kırıcı, ${ }^{1}$ Meltem Çolak Topçu, ${ }^{2}$ Ertuğrul Karataş ${ }^{2}$ \\ 'Dentist, Private Practice \\ ${ }^{2}$ Department of Endodontics, Atatürk University Faculty of Dentistry, Erzurum, Turkey
}

\begin{abstract}
Objective: The aim of our study was to compare the effect of use of different glide path systems before root canal preperation with WaveOne System on dentinal crack development.

Methods: For this study one hundred fifty molars with mesial roots curvatures of $20^{\circ}-40^{\circ}$ were selected. All the other teeth were divided randomly into 9 groups with 15 teeth in each. These groups were: K-type file, PathFile, G-files, Proglider, Pathfile/ WaveOne, G-File/WaveOne, Proglider/WaveOne, K-file/WaveOne and WaveOne. After preparation teeth were sectioned horizontally at 1, 2, 3, 4, 5, 6, and $9 \mathrm{~mm}$ levels and the samples were examined for identifying dentinal crack formation with a stereomicroscope at a $\times 15$ magnification. Dentinal crack formation in samples were statistically analyzed using chi-square test.

Results: The control, hand file, and PathFile groups did not show any dentinal cracks. WaveOne and G file/WaveOne groups led to highest rate of crack formation $(p<.05)$. There was a significant difference between the control/hand file/Pathfile groups and the all other groups $(p<.05)$.
\end{abstract}

Conclusion: WaveOne and $\mathrm{G}$ file/WaveOne groups led to highest rate of crack formation.

Keywords: Dentinal crack; G files; glide path; ProGlider; WaveOne.

E ndodontic glide path which has been defined as a smooth radicular tunnel from the canal orifice of the canal to the apical foramene of the root canal, is important for safer use of $\mathrm{Ni} \mathrm{Ti}$ rotary instrumentation in the curved canals. ${ }^{[1,2]}$ The glide path preparation can prevent instrument fracture and shaping aberrations and it can reduce the risk of taper lock and frictional forces to the canal walls. ${ }^{[3-5]}$ The glide path can be achieved with both hand and rotary instruments; ${ }^{[2]}$ however, the performance of this procedure using hand files may be difficult and timeconsuming, particularly in teeth with constricted and/or severely curved canals..$^{[3]}$ Hence, recent investigations have focused on nickel-titanium (NiTi) rotary instruments to achieve a safe and predictable glide path.

Rotary pathfinding NiTi instruments have been introduced with the purpose of creating an initial glide path and eliminating the need for manual pre-flaring. PathFile (Dentsply Maillefer, Ballaigues, Switzerland), and G-File (Micro-Mega, Besanc, on Cedex, France), are endodontic rotary pathfinding instruments manufactured from conventional NiTi. PathFile system consists of three instruments with ISO 13, 16 and 19 tip sizes, a 0.02 taper. G File System consists of two instruments with ISO 12 and 19 tip sizes, a 0.03 taper. ProGlider NiTi rotary instrument (PG; Dentsply Maillefer, Ballaigues, Switzerland)

Correspondence: Dr. Damla Kırıcı. Atatürk Universitesi, Dişhekimliği Fakültesi,

Endodonti Anabilim Dalı, Erzurum, Turkey.

Tel: +90 505 - 8168470 e-mail: d_ozsu@hotmail.com

Submitted: December 01, 2016 Accepted: December 10, 2016 
and is a novel single-file rotary pathfinding system and it consists of a single instrument with a variable progressive taper. It is manufactured using M-Wire NiTi alloy to enhance flexibility and cyclic fatigue resistance as claimed by the manufacturer. The PG instrument is available in 21 , 25 and $31 \mathrm{~mm}$ length and tip size 16 with a taper of .02 (Dentsply Maillefer 2014).

The purpose of this study was to evaluate the effect of different glide path $\mathrm{Ni}-\mathrm{Ti}$ rotary systems on formation of dentinal crack during root canal preparation using single file system Wave-One in curved canals.

\section{Materials and methods}

Ninety first and second human mandibular molars with curved mesial canals (angles between 25 and 35) extracted for periodontal reasons were stored in physiological saline solution until use. Proximal radiographs were taken, and a mezial root having two separate root canals and two separate apical foramina was included for this study. The distal root of each tooth was removed with a diamond disk, together with the coronary portion exceeding the length of $15 \mathrm{~mm}$. All the roots were inspected with a stereomicroscope (Novex, Arnhem, The Netherlands) with $\mathrm{x} 12$ magnification to detect any preexisting external defects or cracks. Teeth with such defects, resorption or anatomic irregularities were excluded from the study and were replaced with similar teeth. For standardization, the $\mathrm{MD}$ and $\mathrm{BL}$ diameters $9 \mathrm{~mm}$ to the apex of all samples were measured and and 6 groups were formed of 15 teeth each. The homogeneity of the 6 groups with respect to the canal width and angle was assessed by using analysis of variance $(p=1.000)$. Fifteen teeth were left unprepared as a control group. In all the teeth, the canal width near the minor apical foramen was compatible with a size $10 \mathrm{~K}$-file and the working length was determined at $1 \mathrm{~mm}$ shorter than the apical foramen.

The surface of the roots was coated with a silicone impression material to simulate the periodontal ligament space. All the roots were then embedded in acrylic blocks. Seventy-five teeth were instrumented using WaveOne reciprocating single file (25/.08) at the full WL.

\section{Root canal instrumentation}

The preparations were performed by a single operator specialized in endodontics as follows. In all groups, the instruments were used up to their total working length. During root canals were instrumented using WaveOne file (25/.08) with the WaveOne all program of the endodontic motor (X Smart Plus) The WaveOne file was used in a reciprocating, slow, in-and-out pecking motion according to the manufacturer's instructions. After three pecking motions, the file was removed and cleaned with gauze, and the canal was irrigated with distilled water. These procedures were repeated until the file reached the WL.

Group K-type files: The root canals were instrumented with 15 and 20 K-files to create glide path.

Group Pathfile: The root canals were instrumented with PathFile system to create glide path.

Group G file: The root canals were instrumented with $\mathrm{G}$ Files system to create glide path.

Group Proglider: The root canals were instrumented with ProGlider file to create glide path. Group 5 PathFile/WaveOne: Glide path was created with Pathfile system and canals were shaped with WaveOne Primary.

Group G file/WaveOne: Glide path was created with $\mathrm{G}$ Files system and canals were shaped with WaveOne Primary.

Group Proglider/WaveOne Glide path was created with ProGlider file and canals were shaped with WaveOne Primary.

Group Kfile/WaveOne: Glide path was created with 15 and $20 \mathrm{~K}$ file and canals were shaped with WaveOne Primary.

Table 1. Specimens with cracks

\begin{tabular}{|c|c|c|c|c|c|c|c|c|}
\hline Groups & $1 \mathrm{~mm}$ & $2 \mathrm{~mm}$ & $3 \mathrm{~mm}$ & $4 \mathrm{~mm}$ & $5 \mathrm{~mm}$ & $6 \mathrm{~mm}$ & $9 \mathrm{~mm}$ & Specimens with crack \\
\hline Control & 0 & 0 & 0 & 0 & 0 & 0 & 0 & 0 \\
\hline K file & 0 & 0 & 0 & 0 & 0 & 0 & 0 & 0 \\
\hline ProGlider & 0 & 0 & 0 & 0 & 0 & 1 & 1 & 2 \\
\hline G Files & 0 & 1 & 1 & 1 & 1 & 0 & 0 & 4 \\
\hline PathFile & 0 & 0 & 0 & 0 & 0 & 0 & 0 & 0 \\
\hline WaveOne & 1 & 2 & 1 & 1 & 4 & 5 & 7 & 21 \\
\hline WaveOne+K files & 1 & 1 & 1 & 0 & 1 & 1 & 1 & 6 \\
\hline WaveOne+ProGlider & 0 & 1 & 1 & 0 & 1 & 1 & 1 & 5 \\
\hline WaveOne+G Files & 0 & 3 & 2 & 3 & 4 & 5 & 5 & 22 \\
\hline WaveOne+PathFile & 0 & 0 & 0 & 2 & 2 & 3 & 2 & 9 \\
\hline
\end{tabular}



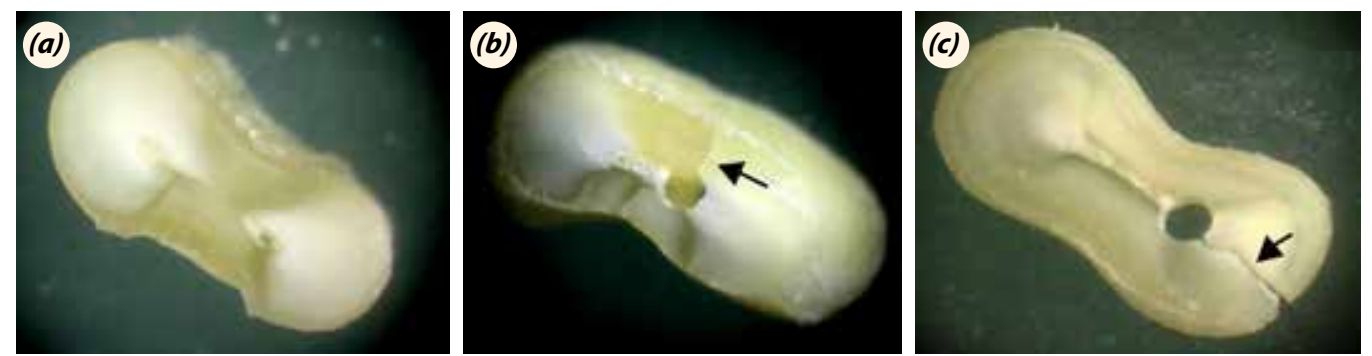

Fig. 1. Examples of microscopic views of samples (a) Section with no defect. (b) Section representing a complete crack. (c) Section representing a complete crack.

Group WaveOne: Glide path was not performed and canals were shaped with WaveOne Primary only

Group WaveOne: The root canals were instrumented by using a WaveOne reciprocating single file (25/.08) with a gentle in-and-out pecking motion and a X Smart Plus endodontıc motor.

Following root canal preparation all roots were cut horizontally at 1, 2, 3, 4, 5, 6 and $9 \mathrm{~mm}$ from the apex with a low-speed saw under constant water-cooling. Allthe sections were then viewed under stereomicroscope at x25 magnification. The samples were photographed with a camera (Nikon Coolpix 4500; Nikon Tokyo, Japan) to determine the presence of dentinal cracks. A total of 105 slices were examined in each group. No defect' was defined as root dentine devoid of any craze lines or microcracks originating from the canal lumen. 'Defect' was defined if any craze lines, microcracks or fractures were present originating from root canal lumen (Figure 1).

The results were expressed as the number and percentage of slices that had cracks in each group. The data were analysed with a chi-square test. All statistical analyses were performed using IBM SPSS Statistics 20 software (IBM SPSS Inc, Chicago, USA)at a 95\% confidence level $(p=0.05)$.

\section{Results}

No cracks were found in the control group. There was significant difference between the control and the all other groups (Figure 2). WaveOne and G file/WaveOne groups led to highest rate of crack formation (Table 1). The incidence of dentinal defects amongst the groups was not different at the apical $(1 \mathrm{~mm}, 2 \mathrm{~mm}, 3 \mathrm{~mm}$ and $4 \mathrm{~mm}$ ) levels. The WaveOne and WaveOne/Gfiles groups produced significantly more cracks than the control, Proglider/WaveOne, Pathfile/ WaveOne and $\mathrm{K}$ file/WaveOne groups at the 6 and $5 \mathrm{~mm}$ levels.

\section{Discussion}

The use of nickel-titanium (NiTi) instruments during root canal preparation causes cracks in root dentine. ${ }^{[6-8]}$ Coronal enlargement and pre-flaring to produce a glide path have been recommended as the initial procedures for safe use of NiTi rotary instrumentation as they prevent taper lock, shaping aberrations, fracture of instruments and excessive instrument binding in root canal. ${ }^{[1,9,10]}$ The dentinal crack formation may increase due to the excessive instrument binding and the maximum contact between the file and dentin. Therefore, the present study aimed to

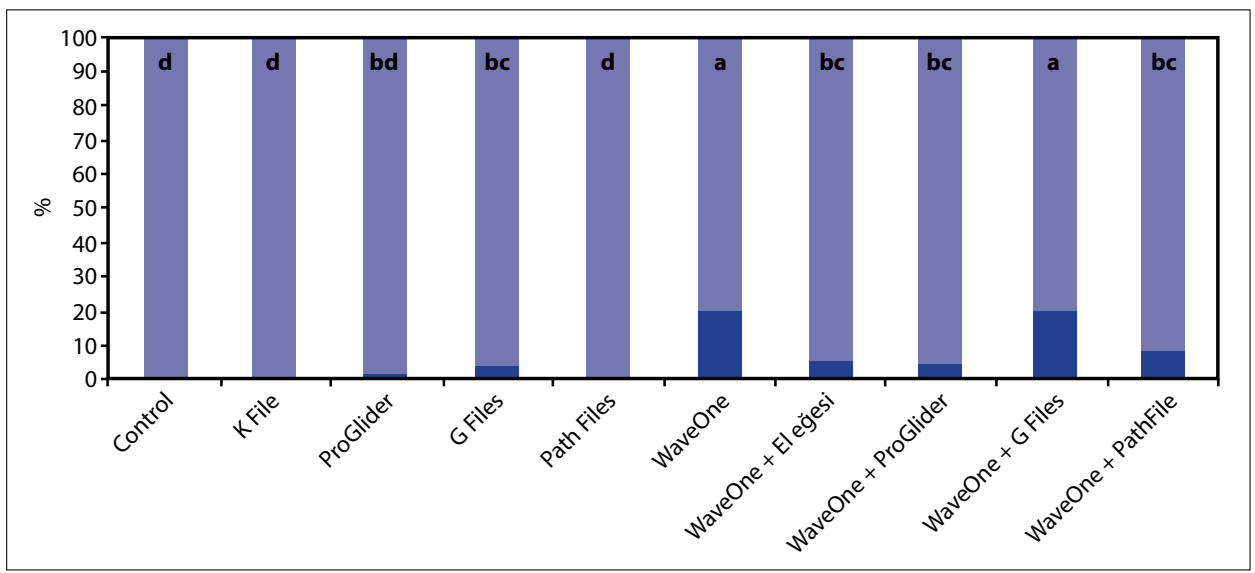

Fig. 2. The numbers of roots with cracks according to the groups. Therewas a significant difference between the groups with different letters $(\mathrm{p}<.05)$. The incidence of cracks were $20 \%$ for WaveOne, $5.7 \%$ for Kfile/ WaveOne, $16.6 \%$ for ProGlider/WaveOne, $4.7 \%$ for Pathfile/WaveOne, and \%21 for Gfile/WaveOne. 
compare of the effect of different glide path Ni-Ti rotary systems on formation of dentinal crack on curved root canals.

The samples were carefully selected for this study. Only mesial roots of lower molars with a curvature of 20-400 that had 2 separate canals ending in 2 separate foramina were used. Curved canals were selected for this study because they pose a challenge for glide path management. ${ }^{[1]}$

According to our results, Path file system didn't cause dentinal crack, Proglider and G files caused $2 \%$ and $4 \%$ dentinal cracks. Path files are nontapered, Proglider has progressive tapered design and $\mathrm{G}$ files has $3 \%$ tapered. The different taper design of the files may explain this results. ${ }^{[6]}$

In our study, WaveOne reciprocal system, we used hand file, ProGlider file, PathFile and $G$ files system to create glide path. There were no differences between handfile, Proglider file and Path files group significantly. But Proglider file caused dentinal crack less than the other groups. ProGlider instruments demonstrated a tendency to create a preliminary enlargement of the root canal in the coronal and middle portions due to its progressive tapered design.

Topcuoğlu et al. ${ }^{[12]}$ stated that performing a glide path prior to canal preparation did not change the incidence of apical crack during preparation. They used 13 and 16 tip size pathfiles for glide path preparation. In our study 13, 16 and 19 tip size pathfiles were used for creating glide path. These contradictory results may be attributed to the use of 19 tip size Pathfile.

The teeth included in this study were examined under a stereomicroscope before the start of the experiment to determine the presence of cracks or fractures. Some cracks might have been internal and not visible on the outer surface of the root. However, there were no cracks or fracture formation in the negative control group. This is in agreement with several studies. ${ }^{[6-8]}$

Thus, it can be concluded that the sectioning method has no effect on crack formation.

Within the limitations of the present study, use of hand file, ProGlider file and PathFile system to create glide path before WaveOne reciprocal system reduced the incidence crack formation in curved root canal.

Conflict of interest: None declared.

\section{References}

1. Patino PV, Biedma BM, Liebana CR, Cantatore G, Bahillo JG. The influence of a manual glide path on the separation rate of NiTi rotary instruments. DEndod 2005;31:114-6.

2. Ha JH, Park SS. Influence of glide path on the screw-in effect and torque of nickel-titanium rotary files in simulated resin root canals. Restor Dent Endod 2012;37:215-9.

3. Ajuz NC, Armada L, Goncalves LS, Debelian G, Siqueira JF. Glide path preparation in S-shaped canals with rotary pathfinding nickel-titanium instruments. J Endod 2013;39:534-7. Crossree

4. Elnaghy AM, Elsaka SE. Evaluation of root canal transportation, centering ratio, and remaining dentin thickness associated with ProTaper Next instruments with and without glide path. J Endod 2014;40:2053-6. Crossse]

5. Roland DD, Andelin WE, Browning DF, Hsu GH, Torabinejad $\mathrm{M}$. The effect of preflaring on the rates of separation for 0.04 taper nickel titanium rotary instruments. J Endod 2002;28:543-5. Crossree

6. Bier CA, Shemesh H, Tanomaru-Filho M, Wesselink PR, $\mathrm{Wu}$ MK. The ability of different nickel-titanium rotary instruments to induce dentinal damage during canal preparation. J Endod 2009;35:236-8. Crossse

7. Yoldas O, Yilmaz S, Atakan G, Kuden C, Kasan Z. Dentinal microcrack formation during root canal preparations by different $\mathrm{NiTi}$ rotary instruments and the self-adjusting file. J Endod 2012;38:232-5. Crossre

8. Hin ES, Wu MK, Wesselink PR, Shemesh H. Effects of self-adjusting file, Mtwo, and ProTaper on the root canal wall. J Endod 2013;39:262-4. Crossset

9. Berutti E, Negro AR, Lendini M, Pasqualini D. Influence of manual preflaring and torque on the failure rate of ProTaper rotary instruments. J Endod 2004;30:228-30. Crossree

10. D’Amario M, Baldi M, Petricca R, De Angelis F, El Abed $R$, D'Arcangelo C. Evaluation of a new nickel-titanium system to create the glide path in root canal preparation of curved canals. J Endod 2013;39:1581-4. Crossret

11. Zhao D, Shen Y, Peng B, Haapasalo M. Root canal preparation of mandibular molars with 3 nickel-titanium rotary instruments: a micro-computed tomographic study. J En$\operatorname{dod} 2014 ; 40: 1860-4$. Crosste

12. Topçuoğlu HS, Düzgün S, Akpek F, Topçuoğlu G. Effect of glide path and apical preparation size on the incidence of apical crack during the canal preparation using Reciproc, WaveOne, and ProTaper Next systems in curved root canals: A stereomicroscope study. Scanning 2016;38:585-90. 